\title{
Asymptotic Solution for a Water Quality Model in a Uniform Stream
}

\author{
Fazle Mabood ${ }^{1}$ and Nopparat Pochai ${ }^{2}$ \\ ${ }^{1}$ Department of Mathematics, Edwardes College Peshawar, Khyber Pakhtunkhwa 25000, Pakistan \\ ${ }^{2}$ Department of Mathematics, Faculty of Science, King Mongkut's University of Technology Ladkrabang, Bangkok 10520, Thailand
}

Correspondence should be addressed to Fazle Mabood; mabood1971@yahoo.com

Received 20 June 2013; Accepted 2 October 2013

Academic Editor: Yurong Liu

Copyright (C) 2013 F. Mabood and N. Pochai. This is an open access article distributed under the Creative Commons Attribution License, which permits unrestricted use, distribution, and reproduction in any medium, provided the original work is properly cited.

\begin{abstract}
We employ approximate analytical method, namely, Optimal Homotopy Asymptotic Method (OHAM), to investigate a onedimensional steady advection-diffusion-reaction equation with variable inputs arises in the mathematical modeling of dispersion of pollutants in water is proposed. Numerical values are obtained via Runge-Kutta-Fehlberg fourth-fifth order method for comparison purpose. It was found that OHAM solution agrees well with the numerical solution. An example is included to demonstrate the efficiency, accuracy, and simplicity of the proposed method.
\end{abstract}

\section{Introduction}

Differential equations have been the focus of many studies due to their frequent appearance in various applications in physics, fluid mechanics, biology, and engineering. Consequently, considerable attention has been given to the solutions of higher order ordinary differential equations, integral equations, and fractional order partial differential equations of physical interest. Number of literatures concerning the application of higher order differential equations in nonlinear dynamics has grown rapidly in the recent years [1-5]. Several numerical and semianalytical methods have been developed for solving high order boundary value problems [6-9].

A mathematical model for the dispersion of pollutants in a river is presented. The optimal homotopy asymptotic method for assessment of the chemical oxygen demand (COD) concentration in a river is considered. Pochai and Tangmanee [10] have provided a mathematical model of water pollution with the help of numerical method. Furthermore, Pochai and coworkers [11-14] have used numerical methods for the solution of hydrodynamic model with constant coefficients in the uniform reservoir and stream.

The optimal homotopy asymptotic method is an approximate analytical tool that is simple and straightforward and does not require the existence of any small or large parameter as does traditional perturbation method. Optimal Homotopy Asymptotic Method (OHAM) has been successfully applied to a number of nonlinear problems arising in fluid mechanics and heat transfer by various researchers [15-19].

This paper is organized as follows. First in Section 2, advection-diffusion-reaction equation is presented. In Section 3 we described the basic principles of OHAM. The OHAM solution of the problem is given in Section 4 . Section 5 is devoted for the concluding remarks.

\section{Dispersion in a Stream}

The dispersion of chemical oxygen demand (COD) is described by the advection-diffusion-reaction equation (ADRE) $[11]$ in the domain $[a, b]$ :

$$
-D_{x} \frac{d^{2} c}{d x^{2}}+u \frac{d c}{d x}+R c-Q=0
$$

where $c(x)$ is the concentration of COD at the point $x \in[a, b]$ $\left(\mathrm{kg} / \mathrm{m}^{3}\right), u=u(x)$ is the flow velocity in the $x$ direction $(\mathrm{m} / \mathrm{s})$, $D_{x}=D(x)$ is the diffusion coefficient $\left(\mathrm{m}^{2} / \mathrm{s}\right), R=R(x)$ is the substance decay rate $\left(\mathrm{s}^{-1}\right)$, and $Q=Q(x)$ is the rate of change of substance concentration due to a source $\left(\mathrm{kg} / \mathrm{m}^{3} \mathrm{~s}\right)$. 
The boundary conditions are

$$
\begin{gathered}
c=c_{0} \quad \text { at } x=a, \\
\frac{d c}{d x}=T_{0} \quad \text { at } x=b .
\end{gathered}
$$

\section{Basic Principles of OHAM}

We review the basic principles of OHAM as illustrated in [3] and other works.

(i) Consider the following differential equation:

$$
A[v(x)]+a(x)=0, \quad x \in \Omega,
$$

where $\Omega$ is problem domain, $A(v)=L(v)+N(v)$, where $L, N$ are linear and nonlinear operators, $v(x)$ is an unknown function, and $a(x)$ is a known function.

(ii) Construct an optimal homotopy equation as

$$
\begin{aligned}
& (1-p)[L(\phi(x ; p))+a(x)] \\
& \quad-H(p)[A(\phi(x ; p))+a(x)]=0,
\end{aligned}
$$

where $0 \leq p \leq 1$ is an embedding parameter and $H(p)=\sum_{i=1}^{m} p^{i} K_{i}$ is auxiliary function on which the convergence of the solution greatly dependents. The auxiliary function $H(p)$ also adjusts the convergence domain and controls the convergence region.

(iii) Expand $\phi\left(x ; p, K_{j}\right)$ in Taylor's series about $p$; one has an approximate solution:

$\phi\left(x ; p, K_{j}\right)=v_{0}(x)+\sum_{k=1}^{\infty} v_{k}\left(x, K_{j}\right) p^{k}, \quad j=1,2,3, \ldots$.

Many researchers have observed that the convergence of the series in (5) depends upon $K_{j}(j=1,2, \ldots, m)$; if it is convergent then, we obtain

$$
\widetilde{v}=v_{0}(x)+\sum_{k=1}^{m} v_{k}\left(x ; K_{j}\right)
$$

(iv) Substitute (6) in (3); we have the following residual:

$$
R\left(x ; K_{j}\right)=L\left(\widetilde{v}\left(x ; K_{j}\right)\right)+a(x)+N\left(\widetilde{v}\left(x ; K_{j}\right)\right) .
$$

If $R\left(x ; K_{j}\right)=0$, then $\widetilde{v}$ will be the exact solution. For nonlinear problems, generally, this will not be the case. For determining $K_{j}(j=1,2, \ldots, m)$, collocation method, Ritz method, or the method of least squares can be used.

(v) Finally, substitute these constants in (6) and one can get the approximate solution.

\section{Application of OHAM}

Consider the advection-dispersion-reaction equation (1) in the form

$$
c^{\prime \prime}=p(x) c^{\prime}+q(x) c+r(x) .
$$

We assume that there is a plant which discharges waste water into the channel at the starting point $0.0 \mathrm{~km}$ and that the COD concentrations of the waste water are $1.2500 \mathrm{~kg} / \mathrm{m}^{3}$. Let the physical parameter values be diffusion coefficient 2 , flow velocity $u(x)=5-x \mathrm{~m} / \mathrm{s}$, where $x \in[0,2]$, substance decay rate $3 \mathrm{~s}^{-1}$, and rate of change of substance concentration due to the source $1 \mathrm{~kg} / \mathrm{m}^{3} \mathrm{~s}$; we can obtain variable coefficients of convection-diffusion equation (8) as

$$
\begin{gathered}
p(x)=\frac{5-x}{D_{x}}=\frac{5-x}{2}, \\
q(x)=\frac{R}{D_{x}}=\frac{3}{2}, \\
r(x)=\frac{-Q}{D_{x}}=\frac{-1}{2} .
\end{gathered}
$$

Equation (8) becomes

$$
c^{\prime \prime}=\frac{5-x}{2} c^{\prime}+\frac{3}{2} c-\frac{1}{2},
$$

subject to the boundary conditions:

$$
\begin{gathered}
c \longrightarrow 1.25 \text { at } x=0, \\
c^{\prime} \longrightarrow 0 \quad \text { at } x=2,
\end{gathered}
$$

where primes denote differentiation with respect to $x$.

According to OHAM, we have

$$
\begin{gathered}
L(\phi(x, p))=\frac{d^{2}}{d x^{2}} c(x, p)-\frac{5}{2} \frac{d}{d x} c(x, p)-\frac{3}{2} c(x, p), \\
a(x)=\frac{1}{2} .
\end{gathered}
$$

Zeroth order problem is

$$
c_{0}^{\prime \prime}-\frac{5}{2} c_{0}^{\prime}-\frac{3}{2} c_{0}+\frac{1}{2}=0,
$$

with boundary conditions:

$$
c_{0}(0)=1.25, \quad c_{0}{ }^{\prime}(2)=0 .
$$

The solution of (13) with boundary conditions (14) is

$$
c_{0}(x)=\frac{77 e^{3 x}}{12\left(6 e^{7}+1\right)}+\frac{1}{3} .
$$

First order problem is

$$
\begin{gathered}
\frac{-5}{2} c_{1}^{\prime \prime}\left(x, K_{1}\right)+c_{1}^{\prime \prime}\left(x, K_{1}\right)-\frac{3}{2} c_{1}\left(x, K_{1}\right) \\
-\frac{11 x K_{1}}{8}\left(\frac{e^{3 x}-e^{(14-x) / 2}}{6 e^{7}+1}\right)=0
\end{gathered}
$$


TABLE 1: Comparison of $c(x)$ via OHAM and numerical method.

\begin{tabular}{lcc}
\hline$x$ & RKF45 & OHAM \\
\hline 0.0 & 1.2500 & 1.2500 \\
0.1 & 1.2031 & 1.2031 \\
0.2 & 1.1580 & 1.1580 \\
0.3 & 1.1147 & 1.1146 \\
0.4 & 1.0731 & 1.0731 \\
0.5 & 1.0333 & 1.0332 \\
0.6 & 0.9952 & 0.9951 \\
0.7 & 0.9588 & 0.9588 \\
0.8 & 0.9242 & 0.9242 \\
0.9 & 0.8914 & 0.8913 \\
1.0 & 0.8604 & 0.8602 \\
1.1 & 0.8313 & 0.8310 \\
1.2 & 0.8042 & 0.8037 \\
1.3 & 0.7792 & 0.7784 \\
1.4 & 0.7564 & 0.7553 \\
1.5 & 0.7362 & 0.7347 \\
1.6 & 0.7187 & 0.7167 \\
1.7 & 0.7042 & 0.7016 \\
1.8 & 0.6832 & 0.6899 \\
1.9 & 0.6862 & 0.6821 \\
\hline
\end{tabular}

with boundary conditions:

$$
c_{1}(0)=0, \quad c_{1}^{\prime}(2)=0 .
$$

The solution of (16) with boundary conditions (17) is

$$
\begin{aligned}
c_{1}\left(x, K_{1}\right)= & \frac{-11 K_{1}\left(e^{3 x+7}-e^{-x / 2}\right)}{343\left(6 e^{7}+1\right)} \\
& +\frac{1}{\left(16464 e^{7}+2744\right)} \\
& \times\left(539 K_{1}\left(x^{2}-\frac{4 x}{7}+\frac{8}{49}\right) e^{3 x}\right. \\
& \left.\quad+\left(\frac{4 x}{7}+\frac{8}{49}+x^{2}\right) e^{(14-x) / 2}\right) .
\end{aligned}
$$

The terms of second order problem and its solution are too large to be written above; therefore the final three-term solution via OHAM for $p=1$ is

$$
\tilde{c}\left(x, K_{1}, K_{2}\right)=c_{0}(x)+c_{1}\left(x, K_{1}\right)+c_{2}\left(x, K_{1}, K_{2}\right) .
$$

We use the method of least squares to obtain $K_{1}$ and $K_{2}$, the unknown convergent constants in $\widetilde{c}$. The values of the convergent constants are $K_{1}=0.001881235287, K_{2}=$ -1.103025681 .

By substituting the values of $K_{1}$ and $K_{2}$ in (19) and after simplification, we obtain the second order approximate solution via OHAM. To check the accuracy of the OHAM solution, a comparison between the solutions obtained by OHAM and numerical method was made and is presented in Table 1. Graphical representation of the solution using OHAM and Runge-Kutta-Fehlberg-fourth fifth order method is shown in Figure 1; an excellent agreement can be observed.

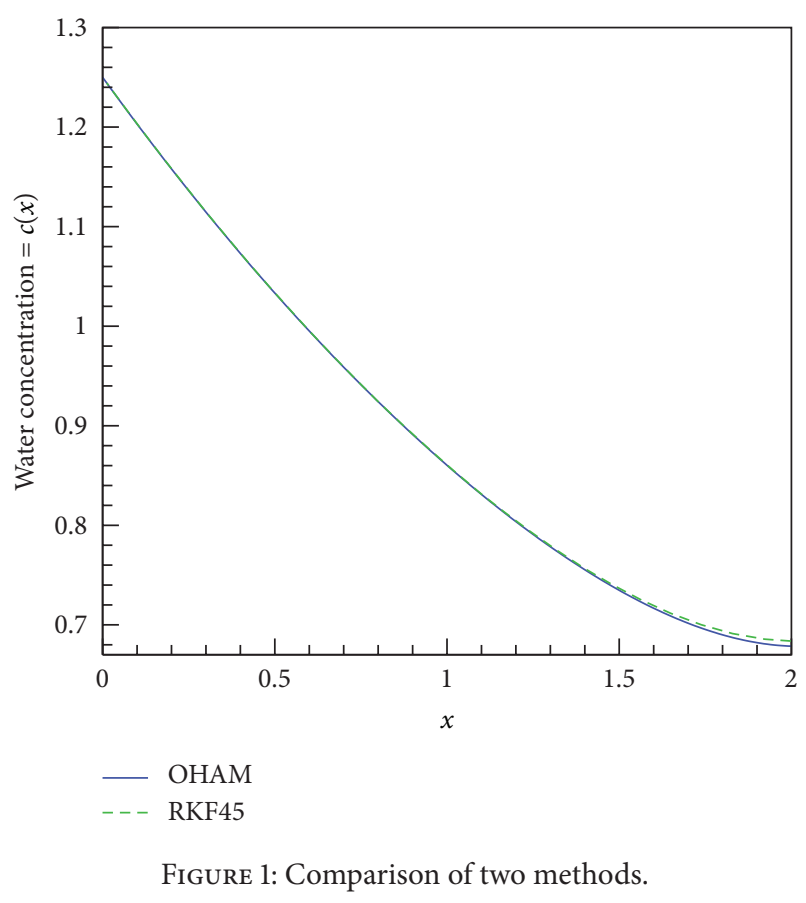

\section{Concluding Remarks}

In this paper, we have presented the solution of the onedimensional steady advection-diffusion-reaction equation with variable inputs using homotopy approach and RungeKutta-Fehlberg fourth-fifth order method. Both approximate analytical and numerical results are obtained for the given problem. The validity of the proposed procedure, called the Optimal Homotopy Asymptotic Method (OHAM), was demonstrated on an example, and very good agreement was found between the approximate analytic results and numerical simulation results. The proposed scheme provides us with a simple and accurate way to optimally control and adjust the convergence of a solution and can give very good approximations in a few terms.

\section{References}

[1] A.-M. Wazwaz, "The modified decomposition method and Padé approximants for a boundary layer equation in unbounded domain," Applied Mathematics and Computation, vol. 177, no. 2, pp. 737-744, 2006.

[2] S. Awang Kechil and I. Hashim, "Approximate analytical solution for MHD stagnation-point flow in porous media," Communications in Nonlinear Science and Numerical Simulation, vol. 14, no. 4, pp. 1346-1354, 2009.

[3] V. Marinca and N. Herisanu, "Optimal homotopy perturbation method for strongly nonlinear differential equations," Nonlinear Science Letters A, vol. 1, no. 3, pp. 273-280, 2010.

[4] B. Bradie, A Friendly Introduction To Numerical Analysis, Pearson Education, Upper Saddle River, NJ, USA, 2006.

[5] F. Mabood, A. I. M. Ismail, and I. Hashim, "The application of optimal homotopy asymptotic method for the approximate solution of Riccati equation," Sains Malaysiana, vol. 42, no. 6, pp. 863-867, 2013. 
[6] G. Adomian, "A new approach to nonlinear partial differential equations," Journal of Mathematical Analysis and Applications, vol. 102, no. 2, pp. 420-434, 1984.

[7] J.-H. He, "Asymptotology by homotopy perturbation method," Applied Mathematics and Computation, vol. 156, no. 3, pp. 591596, 2004.

[8] S. J. Liao, The proposed homotopy analysis technique for the solution of nonlinear problem [Ph.D. thesis], Shanghai Jiao Tong University, 1992.

[9] V. Marinca and N. Herişanu, "Application of optimal homotopy asymptotic method for solving nonlinear equations arising in heat transfer," International Communications in Heat and Mass Transfer, vol. 35, no. 6, pp. 710-715, 2008.

[10] N. Pochai and S. Tangmanee, "A mathematical model of water pollution using finite element method," Contributions in Mathematics and Applications, East-West J. Math. Spec., 143154, 2007.

[11] N. Pochai and R. Depana, "An optimal control of water pollution in a stream using a finite difference method," World Academy of Science, Engineering and Technology, vol. 6, no. 56, pp. 1186-1188, 2011.

[12] N. Pochai, S. Tangmanee, L. J. Crane, and J. J. H. Miller, "A Mathematical model of water pollution using finite element method," Proceedings in Applied Mathematics and Mechanics, vol. 6, pp. 755-756, 2006.

[13] N. Pochai, "A numerical computation of the non-dimensional form of a non-linear hydrodynamic model in a uniform reservoir," Nonlinear Analysis: Hybrid Systems, vol. 3, no. 4, pp. 463-466, 2009.

[14] N. Pochai, "A numerical computation of a non-dimensional form of stream water quality model with hydrodynamic advection-dispersion-reaction equations," Nonlinear Analysis: Hybrid Systems, vol. 3, no. 4, pp. 666-673, 2009.

[15] N. Herişanu and V. Marinca, "Accurate analytical solutions to oscillators with discontinuities and fractional-power restoring force by means of the optimal homotopy asymptotic method," Computers and Mathematics with Applications, vol. 60, no. 6, pp. 1607-1615, 2010.

[16] S. Islam, F. Mabood, G. Zaman, X.-Z. Li, and I. H. Jung, "Optimal homotopy asymptotic method solution to convection heat transfer flow," International Journal of Physical Sciences, vol. 6, no. 23, pp. 5511-5519, 2011.

[17] S. Islam, R. Ali Shah, I. Ali, and N. M. Allah, "Optimal homotopy asymptotic solutions of couette and poiseuille flows of a third grade fluid with heat transfer analysis," International Journal of Nonlinear Sciences and Numerical Simulation, vol. 11, no. 6, pp. 389-400, 2010.

[18] F. Mabood, W. A. Khan, and A. I. M. Ismail, "Optimal homotopy asymptotic method for heat transfer in hollow sphere with robin boundary conditions," Heat Transfer-Asian Research, 2013.

[19] F. Mabood, W. A. Khan, and A. I. M. Ismail, "Analytical solution for radiation effects on heat transfer in blasius flow," International Journal of Engineering Science, vol. 2, no. 2, pp. 6372, 2013. 


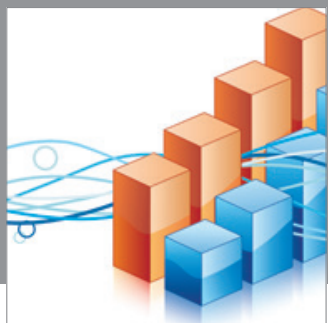

Advances in

Operations Research

mansans

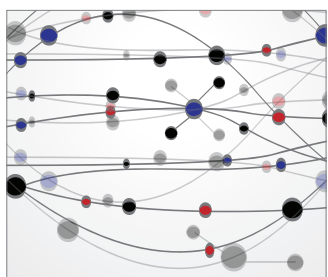

The Scientific World Journal
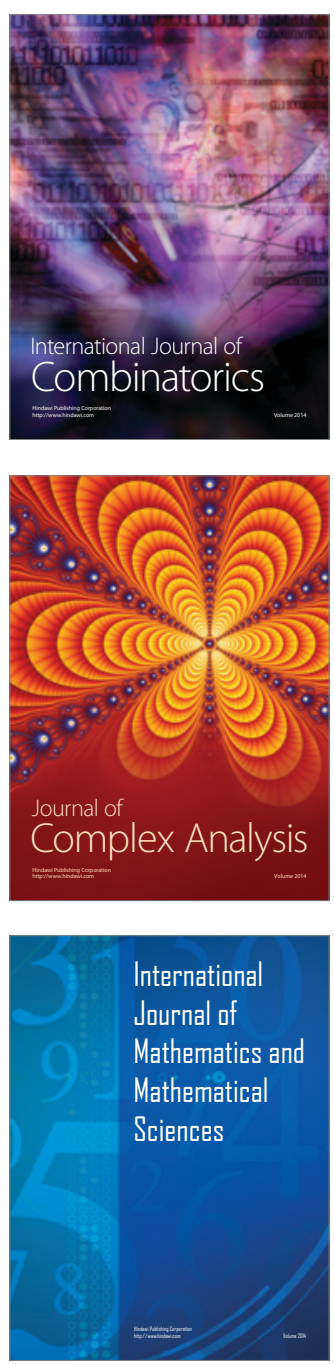
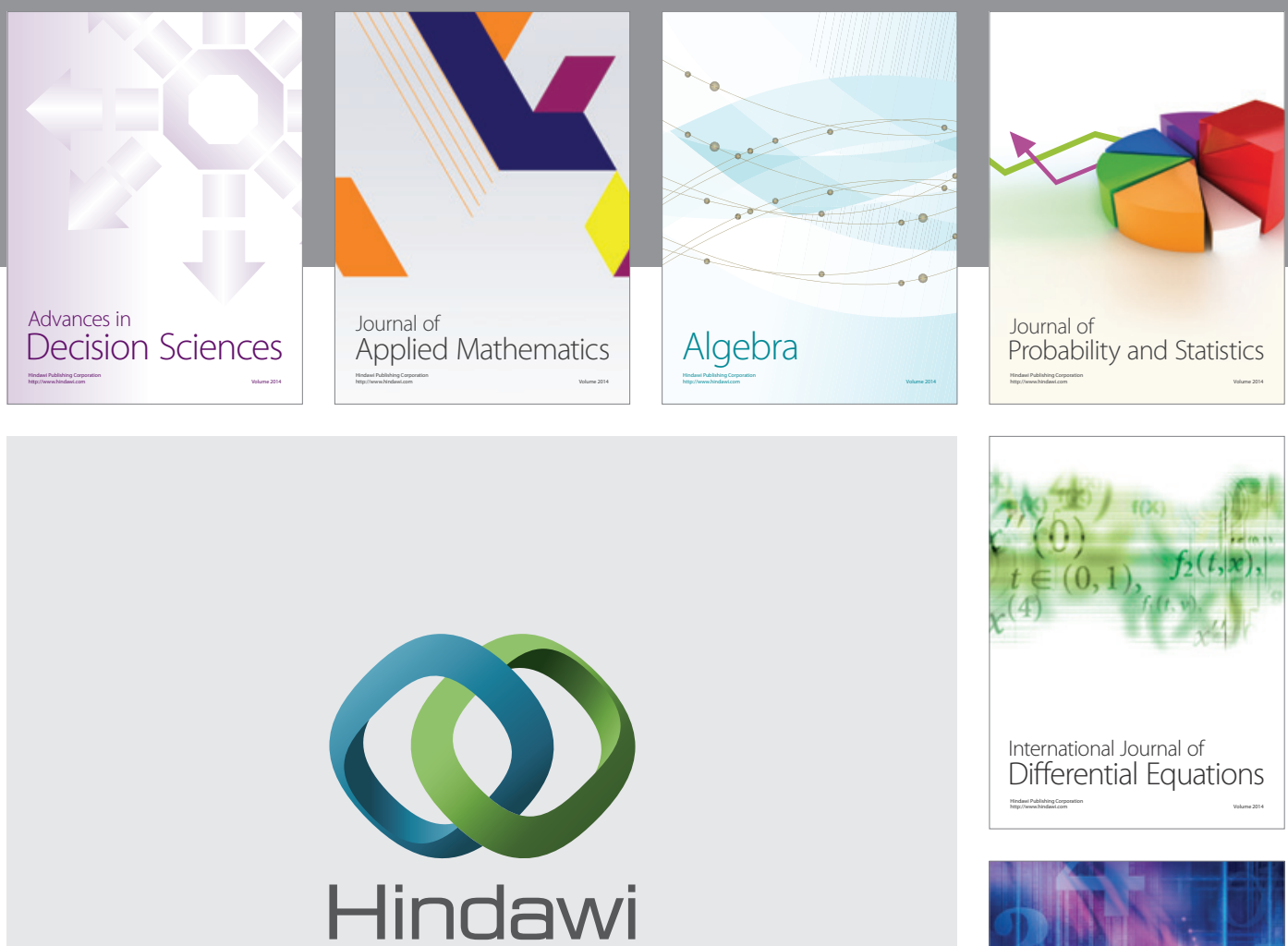

Submit your manuscripts at http://www.hindawi.com
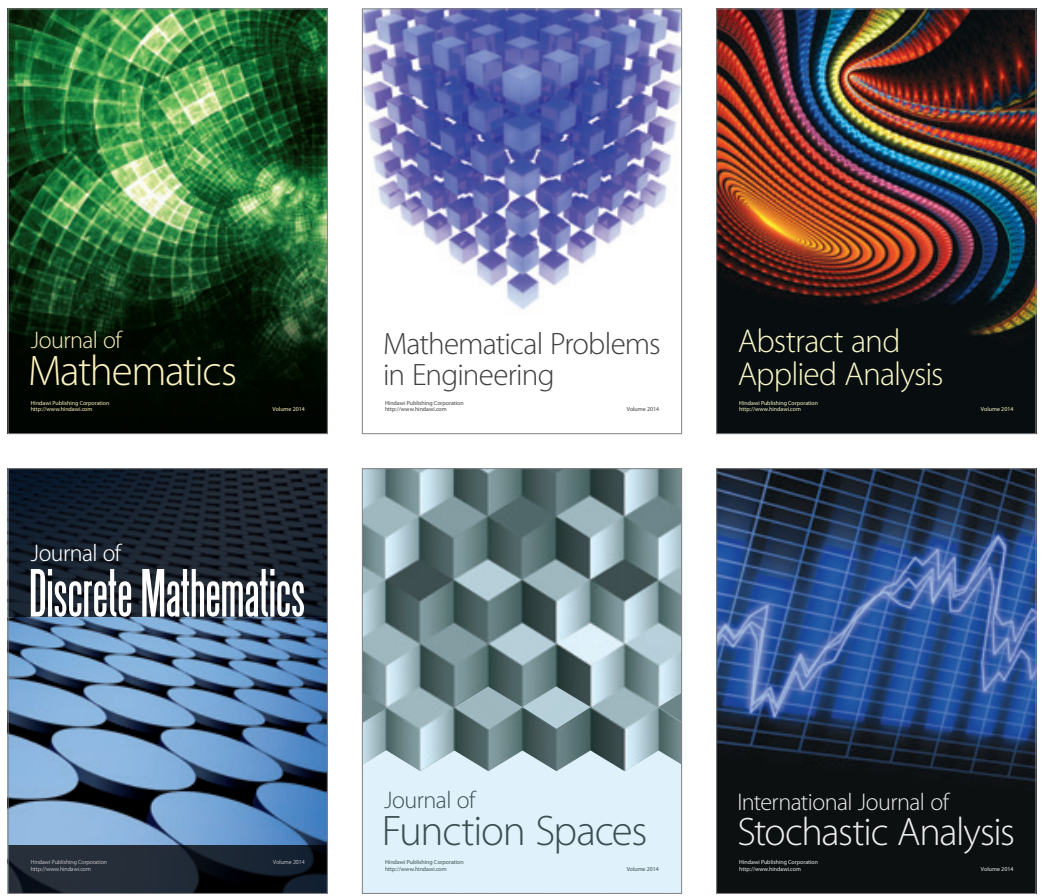

Journal of

Function Spaces

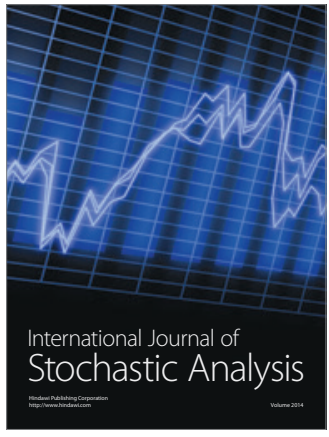

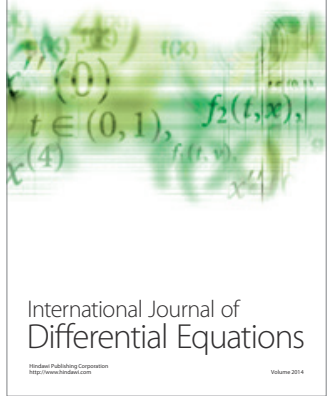
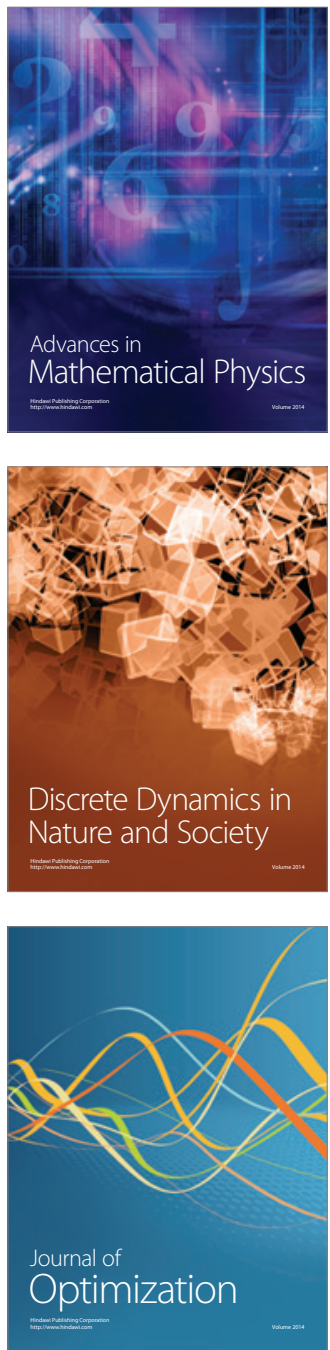